\title{
Optimization of Truss Girders in Cable-Supported Bridges including Stability
}

\author{
Baandrup, Mads ; Poulsen, Peter Noe; Olesen, John Forbes; Polk, Henrik
}

Published in:

Journal of Bridge Engineering

Link to article, DOI:

10.1061/(ASCE)BE.1943-5592.0001632

Publication date:

2020

Document Version

Peer reviewed version

Link back to DTU Orbit

Citation $(A P A)$ :

Baandrup, M., Poulsen, P. N., Olesen, J. F., \& Polk, H. (2020). Optimization of Truss Girders in Cable-Supported Bridges including Stability. Journal of Bridge Engineering, 25(11), [04020099].

https://doi.org/10.1061/(ASCE)BE.1943-5592.0001632

\section{General rights}

Copyright and moral rights for the publications made accessible in the public portal are retained by the authors and/or other copyright owners and it is a condition of accessing publications that users recognise and abide by the legal requirements associated with these rights.

- Users may download and print one copy of any publication from the public portal for the purpose of private study or research.

- You may not further distribute the material or use it for any profit-making activity or commercial gain

- You may freely distribute the URL identifying the publication in the public portal 


\title{
Optimization of truss girders in cable-supported bridges including stability
}

\author{
Mads Baandrup ${ }^{1}$, Peter Noe Poulsen ${ }^{2}$, John Forbes Olesen ${ }^{3}$, and Henrik Polk ${ }^{4}$ \\ ${ }^{1}$ Dept. of Civil Engineering, Technical University of Denmark, Kgs. Lyngby 2800, Denmark; \\ Dept. of Major Bridges International, COWI A/S, Parallelvej 2, Kgs. Lyngby 2800, Denmark \\ (corresponding author). Email: mjba@byg.dtu.dk \\ ${ }^{2}$ Dept. of Civil Engineering, Technical University of Denmark, Kgs. Lyngby 2800, Denmark. \\ ${ }^{3}$ Dept. of Civil Engineering, Technical University of Denmark, Kgs. Lyngby 2800, Denmark. \\ ${ }^{4}$ Dept. of Major Bridges International, COWI A/S, Parallelvej 2, Kgs. Lyngby 2800, Denmark.
}

\begin{abstract}
The main design principles for girders in cable-supported bridges have not changed significantly over the past 60 years, and are limited in further development. The design concept suffers from substantial fatigue issues, and will be challenged by self-weight in future very-long bridges with main spans beyond $2 \mathrm{~km}$. In this work, truss topology optimization, including global and local stability, is applied in a conceptual study of new weight-reduced designs for girders in cablesupported bridges. The methods are based on finite element limit analysis and convex optimization. A single section of a continuous girder, subject to local and global loads, is optimized to minimize weight while fulfilling constraints on stresses as well as global and local stability. The optimized designs, significantly different in layout from the conventional, show initial weight savings of up to $45 \%$ compared to the present design. Further parameter studies indicate potential weight savings of up to $54 \%$.
\end{abstract}

\section{INTRODUCTION}

In the past 60 years, the overall structural system for girders in cable-supported bridges have remained nearly unchanged, (Gimsing and Georgakis 2012). The design principles of closed steel 
box girders with orthotropic decks and transverse diaphragms have been applied in the majority of large suspension bridges since the 1950s, (Wolchuk and Harris 1959; Wolchuk 1999). However, the design principles are limited in further development and suffer from substantial fatigue issues, (Fisher and Dexter 1997; Kozy and Connor 2010; Zhang 2017). Fatigue issues are inherent in the design, since loads are carried in one direction at a time, leading to stress concentrations at connections, (Song and Ding 2014). Furthermore, the design concept will be challenged in the future by its weight, since self-weight is crucial for very-long suspension bridges with main spans beyond $2 \mathrm{~km}$, (Gimsing and Georgakis 2012).

Through the years, the conventional design principles have been subject to several studies and improvements, especially with the focus on reducing fatigue issues. Parametric studies have been carried out, both experimentally (Aygül et al. 2012; Oh and Bae 2013), analytically (Backer et al. 2006), and numerically with focus on cutout details in diaphragms (Connor 2004; De Corte 2009; Oh et al. 2011) and the top deck (Fettahoglu 2016). Recently, a new approach to improve the design by gradient-based parametric optimization with the focus on weight minimization has been proposed by (Baandrup et al. 2019). In this study, weight savings of 6\% was achieved for current design practice indicating very little room for improvement without altering the concept. Despite many studies the overall structural system has not changed significantly. No major changes have been introduced to overcome fatigue issues or reduce weight, and thereby increase the potential span length. However, in future designs of suspension bridges with main spans beyond $2 \mathrm{~km}$, it is anticipated that greater and more radical design changes will be required. In this regard, the weight-minimization of the girder is a natural starting point, since the reduced girder weight will have knock-on effects on the supporting bridge components such as cables, towers, and anchor blocks.

In the present paper, an optimization method based on truss structures is utilized as the design tool to identify new conceptual design approaches for girders in cable-supported bridges. The structural layout of a simplified bridge girder model is optimized to reduce weight by the use of truss optimization including global and local stability as well as stress constraints. 
The girder model subject to optimization is a single section $(25 \mathrm{~m} \times 30.1 \mathrm{~m} \times 4.75 \mathrm{~m})$ of the continuous girder in a suspension bridge. Outer geometry, dimensions, and load cases are based on the recently constructed Osman Gazi Bridge, which opened to traffic in July 2016. The basis of the conceptual study is an assumption of a fixed top plate spanning up to $3 \mathrm{~m}$ in two directions and thus distributing the surface loads to an underlying truss structure. The top plate may be constructed as a sandwich element with steel plate skins, see e.g. (Battista et al. 2010; Corte 2011; Chu et al. 2018). However, in the present work, the focus is on the optimization of the supporting truss structure. The model is subject to both local and global load cases, identified from a global beam model of the Osman Gazi Bridge.

The applied optimization method is based on finite element limit analysis (FELA) and convex optimization. FELA is based on the finite element concept and defines a convex linear optimization problem assuming perfect plastic material behavior. The basis of the methods used in the present paper, was introduced in (Poulsen et al. 2020) and developed to handle large-scale structures in (Baandrup et al. 2020), where methods to reduce truss complexity were formulated. These methods are briefly summarized for completeness and ease of understanding.

Subsequently, the basic methods are extended to handle the bridge girder model with novel constraints imposing the assumed top plate, symmetry conditions, and global section forces. Finally, the full problem formulation is applied to the conceptual bridge girder study. The focus of the study is mainly on potential weight reduction and the identification of the overall structural concept. Hence, construction costs and structural details are not taken into account.

The constraints defining the girder model are validated on a simple model, followed by the optimization of the bridge girder subject to two simple load cases. Subsequently, the complete model is optimized to identify new conceptual designs and possible weight savings. Finally, two parametric studies are carried out to study the effect of varying top plate strength and domain height, respectively.

\section{METHODS}

In the following sections, the bridge girder model to be optimized is presented. Here, the 


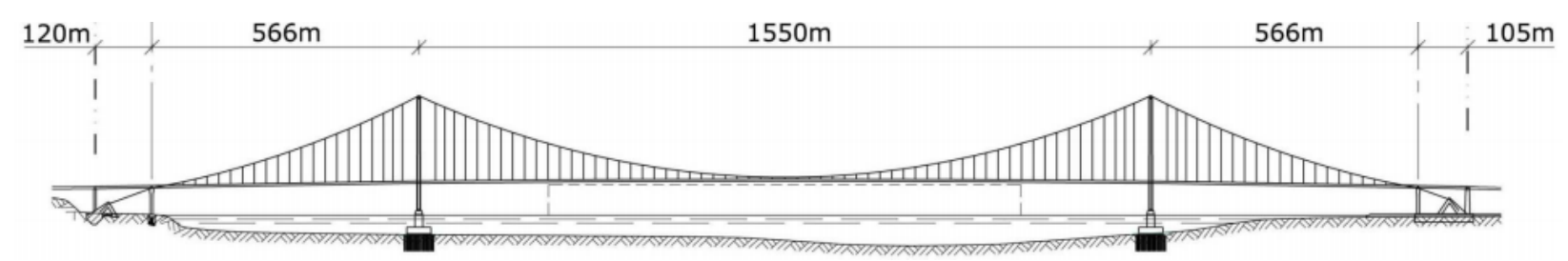

Fig. 1. Main dimensions and layout of the Osman Gazi Bridge (COWI A/S), see, e.g., (Diana et al. 2013)

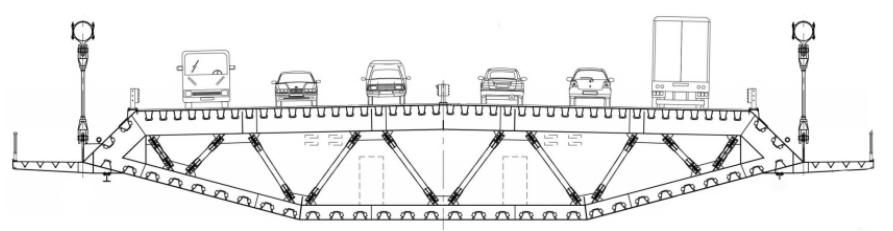

Fig. 2. Design principle of the closed box girder with orthotropic deck and truss diaphragms in the Osman Gazi Bridge (COWI A/S), see, e.g., (Diana et al. 2013)

geometry, load cases, and boundary conditions of the FE-model are introduced together with other assumptions. Subsequently, the main principles of FELA-based truss layout optimization are summarized from (Poulsen et al. 2020). Finally, the implementation, combining the bridge girder model with the FELA optimization framework, is described.

\section{Bridge girder model}

The conceptual optimization study is based on the recently finalized Osman Gazi Bridge, Turkey, which opened to traffic in July 2016 with a main span of $1,550 \mathrm{~m}$. The bridge design, made by COWI A/S, was state-of-the-art and is considered a suitable reference for the development of a new bridge girder design. The main dimensions and layout are seen in Fig. 1. The girder design is a closed steel box-girder with an orthotropic deck and truss diaphragms every five meters, see Fig. 2. In the remaining, this design is designated the conventional design concept.

Since the bridge girder is a continuous structure, only one section ( $L=25 \mathrm{~m}$ equivalent to the distance between two sets of hangers) is modeled. The width of the girder is $W=30.1 \mathrm{~m}$ and the height is $H=4.75 \mathrm{~m}$. The domain and outer dimensions are shown in Fig. 3. The outer geometry of the domain is defined by the outer shape of the original design (without walkway), which is the reason for the inclined edges. The aerodynamic shape of the profile is maintained, 


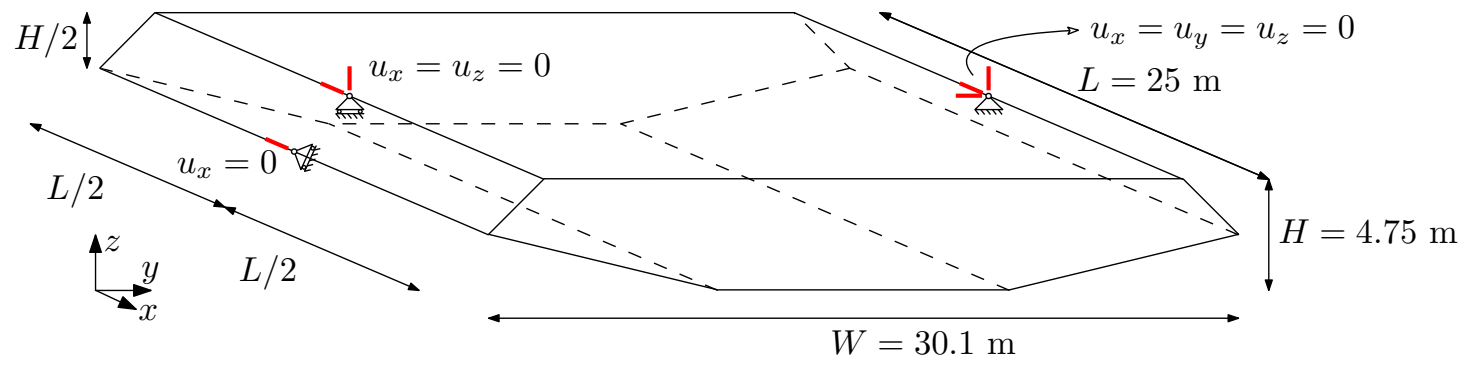

Fig. 3. Domain of one girder section with the indication of dimensions and boundary conditions

since aerodynamic issues are out within the scope of the present study.

The section is part of a continuous girder and the loads applied are in equilibrium. The kinematic boundary conditions, imposed on the six degrees of freedom shown in Fig. 3, are applied to prevent any rigid body motion.

The section is modeled with a top plate and a supporting structure of truss elements. It is assumed that a top plate, necessary to carry the traffic loads, is at hand (e.g. some sandwich structure with steel skins (Battista et al. 2010; Corte 2011; Chu et al. 2018)), spanning up to $3 \mathrm{~m}$ in two directions, distributing the surface loads to the nearest nodes in the underlying truss. The specific design of this top plate is not considered and left for future work. However, in the present work, an equivalent steel plate thickness of $t_{t p}=20 \mathrm{~mm}$ was selected. In the Osman Gazi Bridge, the equivalent plate thickness was $26 \mathrm{~mm}$ for the orthotropic deck (top plate and troughs) spanning 5 $\mathrm{m}$. In the present model, the top plate is modeled as a fixed truss grid in the upper layer, as indicated in Fig. 4. Since this top truss is fixed, it is only the underlying structure which is optimized.

Furthermore, since the bridge girder is a symmetric and repetitive structure, symmetry constraints are applied. Symmetry lines are given along the longitudinal center line and in the transverse center line of each section, as shown in Fig. 5. This utilisation of symmetry significantly reduces the number of unknowns allowing for the modelling of larger systems within given computational limits.

The model is subject to 14 load cases, 12 designated global and two designated local. The applied loads are indicated in Fig. 6 and shown in Table 1 in Appendix I.

The 12 global load cases, LC 1-12, consist of section forces from a global beam model of the 


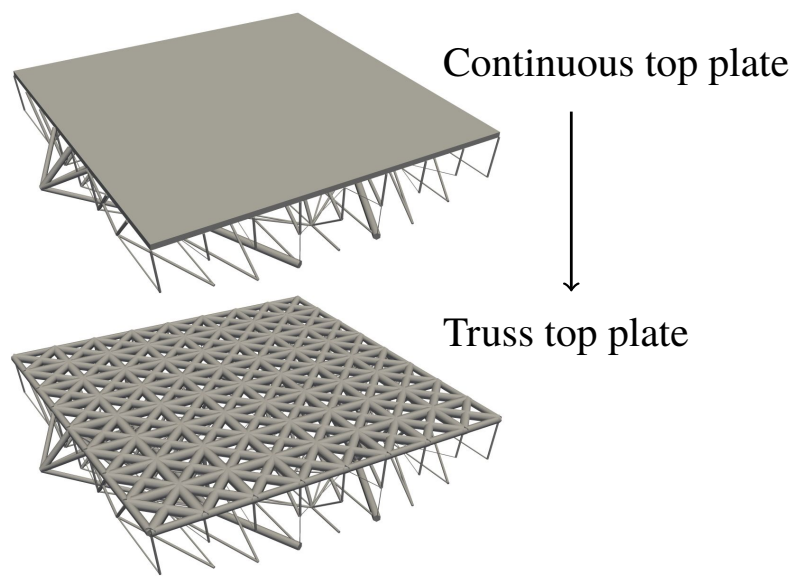

Fig. 4. Assumption of a continuous top plate and equivalent modeled truss top plate

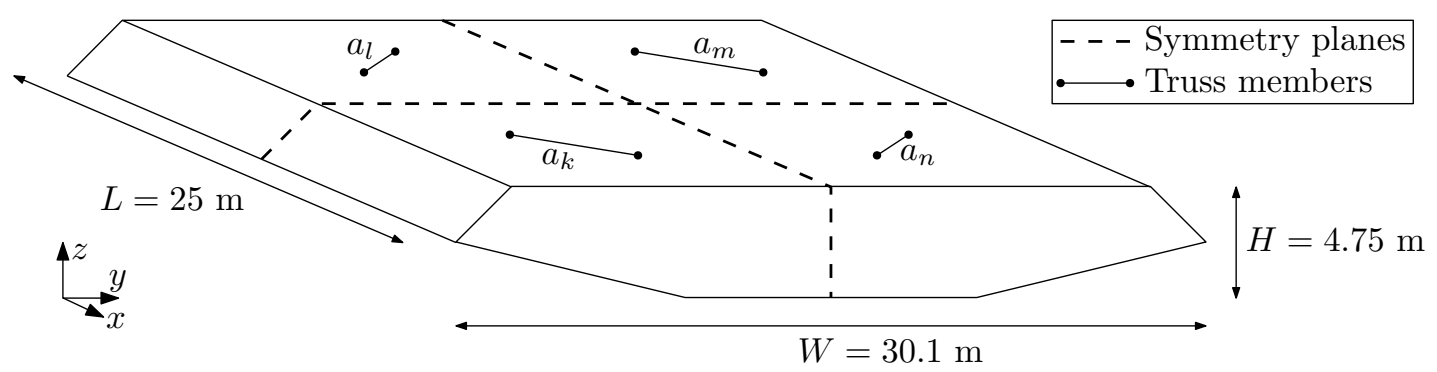

Fig. 5. Symmetry mapping of the structure indicated by truss members with equal area $a_{k}=a_{l}=$ $a_{m}=a_{n}$

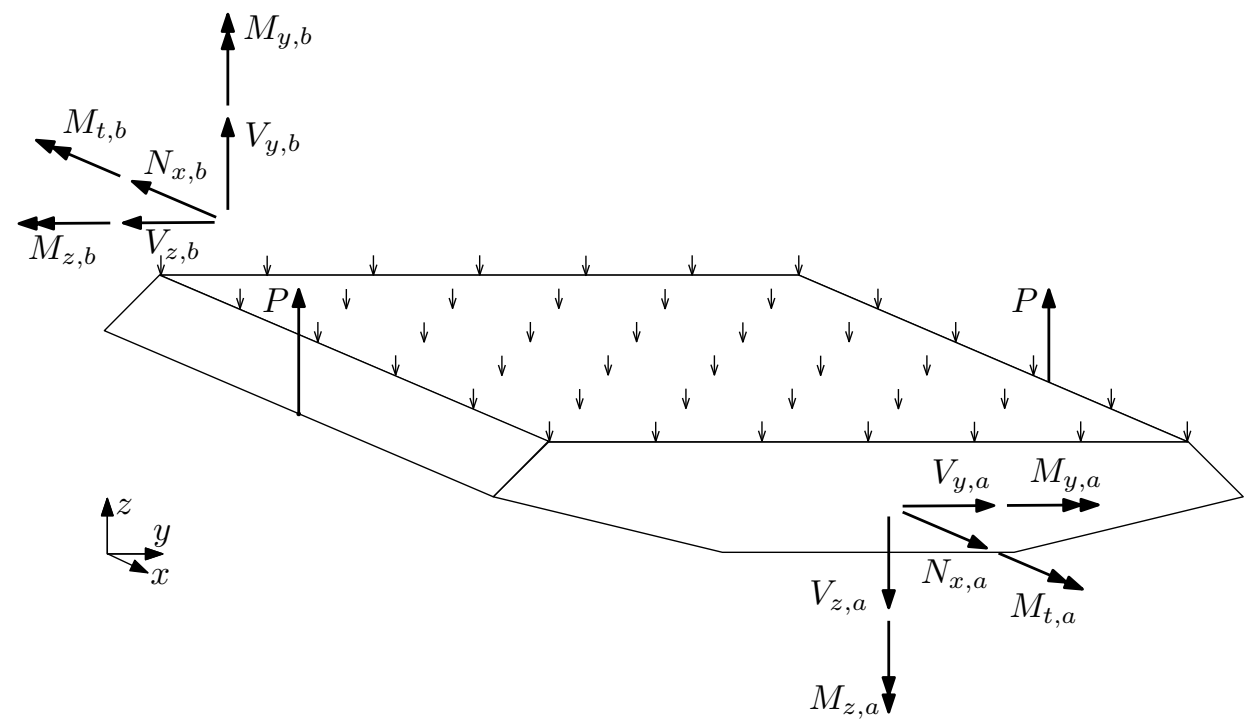

Fig. 6. Global section forces applied to end surfaces, local distributed load $p$ (indicated by downward arrows), and hanger forces $P$ 
bridge. The beam model was developed during the design stage, with the COWI A/S in-house finite element software IBDAS (Integrated Bridge Design and Analysis Software). The model, loads (permanent, traffic, wind, seismic action, and temperature), and load combinations were all based on the Eurocode ((CEN 2002; CEN 2003)) and the UK National Annexes. From the IBDAS beam model, the most critical (static) section forces in typical sections of the girder were identified. In total 12 sets of critical section forces have been identified, equivalent to the maximum and minimum of the six section forces in a beam $\left(N_{x}, M_{y}, M_{z}, V_{y}, V_{z}, M_{t}\right)$. Each set of forces consists of the global section forces acting on each end surface (End $a$ and $b$ ) of the local model, as indicated in Fig. 6. The set of section forces is applied together with the distributed load $p$ on the top surface and hanger forces $P$ to ensure equilibrium of all loads applied. The section forces in the girder and locally distributed load and hanger forces are given by the beam model.

The two local load cases, LC 13 and 14, consist of a downward uniformly distributed load $p=5 \mathrm{kN} / \mathrm{m}^{2}$ with equivalent upward hanger forces $P$ to ensure equilibrium. Additionally, two moments, $M_{y, a}$ and $M_{y, b}$, are applied to the end surfaces to imitate the behavior of the continuous girder. In LC 13 the distributed load is applied to the entire top surface, whereas in LC 14 the load is applied only on one side of the longitudinal center line, to give a skew distribution.

\section{Truss layout optimization including global and local stability}

The bridge girder model is optimized with FELA-based truss layout optimization. The main principles of the applied method were introduced in (Poulsen et al. 2020) and are summarized below.

FELA is a numerical method that combines the discretization of a model, known from conventional finite element analysis (FEA), with limit analysis of structures where rigid-plastic material behavior is assumed as well as small displacements. Normally, displacements are the variables in FEA, whereas the variables in the lower-bound method of FELA are the stresses.

The truss optimization takes the ground-structure approach, and the objective of the optimization is to minimize the total volume (weight) of the truss structure while fulfilling given constraints. The topological design variables are the cross-sectional areas of all members except the ones in the 
top plate.

During the optimization, four different constraints must be fulfilled. Firstly, a constraint ensuring equilibrium of nodal forces for all unsupported nodes, in order to establish an admissible stress field. Secondly, a constraint ensuring that all member stresses are within the yield stress limits. Finally, two different constraints ensuring compliance with restrictions against local and global instability, respectively.

The truss layout optimization problem with the four constraints, as formulated in (Poulsen et al. 2020), is given as the convex problem

$$
\begin{array}{ll}
\min _{\boldsymbol{\beta}, \mathbf{A}} & V=\sum_{e=1}^{N_{e}} a_{e} \ell_{e}=\mathbf{A}^{\top} \mathbf{L} \\
\text { s.t. } & \mathbf{H} \boldsymbol{\beta}=\mathbf{R} \\
& \mathbf{C} \boldsymbol{\beta}-\mathbf{C}_{m} \mathbf{A} \leq \mathbf{0} \\
& -\mathbf{I} \boldsymbol{\beta}-\mathbf{P A} \leq \mathbf{q} \\
& \mathbf{K}_{G}\left(\boldsymbol{\beta}_{k}\right)+\mathbf{K}(\mathbf{A}) \geq 0 \forall k=1, \ldots, N_{k}
\end{array}
$$

where $e$ refers to the $N_{e}$ individual members and $k$ refers to the $N_{k}$ individual load cases. The main design variables are the member areas collected in $\mathbf{A}$ and the secondary design variables are the bar forces collected in $\beta$. The objective function in (1a), defining the total truss volume $V$, is given as the summation of the products of individual member areas $a_{e}$ and lengths $\ell_{e}$ (collected in vector $\mathbf{L}$ ). The first constraint (1b) defines the equilibrium equations, where the equilibrium matrix $\mathbf{H}$ ensures the nodal equilibrium of internal $(\boldsymbol{\beta})$ and external $(\mathbf{R})$ nodal forces for all unsupported nodes. The second constraint (1c) defines the yield condition, or stress constraint. The effect of the constraint may be seen as a conversion of the bar forces to their absolute values $(\mathbf{C})$, which are restricted by the yield stress $f_{y}$, of each bar $\left(\mathbf{C}_{m}\right)$.

The third constraint (1d) defines the restriction against local instability of each element. The constraint is based on the Euler buckling load $P_{c r}$ for a simply supported member. Hence, the 
constraint for element $e$ is given as

$$
-\beta_{e} \leq P_{c r, e}=\frac{\pi^{2} \cdot E I_{e}}{\ell_{e}^{2}} \approx \alpha_{e} a_{e}^{2}
$$

where $E$ is the modulus of elasticity and $I_{e}$ the second moment of area. The rightmost quadratic term is exact for a circular cross-section, for other cross-sectional geometries the expression is an approximation, see (Poulsen et al. 2020). However, the constraint is non-convex, and it cannot be integrated immediately into the convex optimization problem. To eliminate the non-convex properties of (2), the quadratic constraint is linearized by either its tangent or its secant. The linearizations of (2) for all elements and load cases are assembled to give the matrix expression (1d), where $\mathbf{I}$ is the identity matrix, $\mathbf{P}$ is a matrix representing the parts of the linearization which are proportional to $a_{e}$, and $\mathbf{q}$ is a vector containing the constant parts.

The final constraint (1e) defines the restriction against global instability for each of the $N_{k}$ load cases. The constraint is defined as a semidefinite constraint on the linearized buckling stiffness matrix comprised of the sum of the global geometric stiffness matrix $\mathbf{K}_{G}$, which is a function of the bar forces, and the global elastic stiffness matrix $\mathbf{K}$, which is a function of the bar areas.

In (Baandrup et al. 2020) the optimization problem (1) was reformulated to handle large-scale models. The primal formulation (1) was rewritten to its dual formulation, resulting in a large reduction in computational time and memory demand. This technique is applied here too, however, only the primal formulations are shown in the following.

In this conceptual study, emphasis is on practical solutions, and in particular on lowering construction cost, therefore it is desirable to reduce the truss complexity by reducing the number of members and the number of connections (nodes). In (Baandrup et al. 2020) two heuristic methods were formulated to penalize short members and members with small cross-sectional areas. The methods are applied here, too, to reduce structural complexity. 


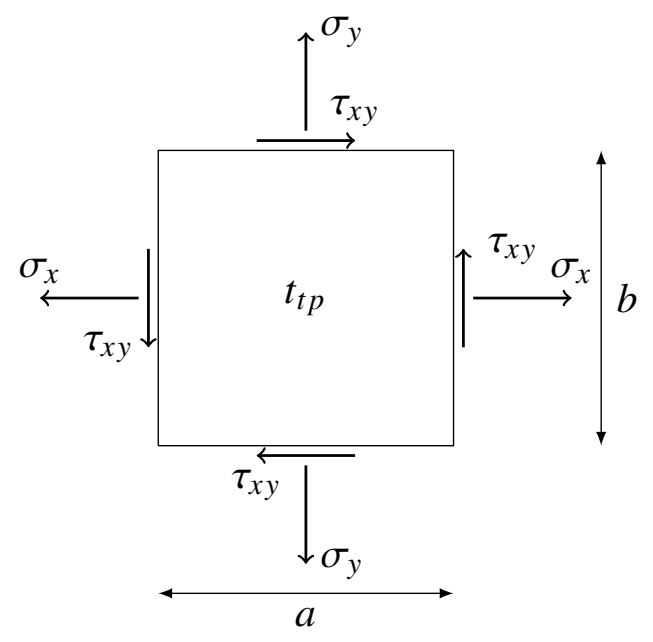

(a) Plate structure

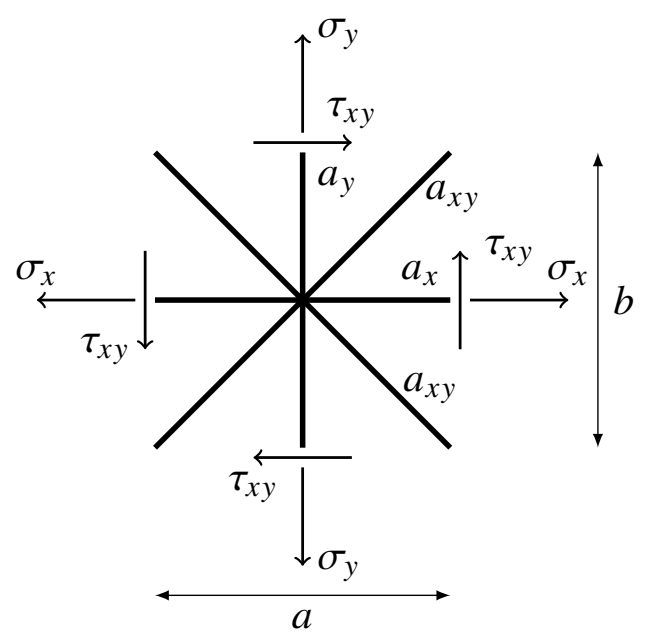

(b) Truss structure with representative grid elements

Fig. 7. Structural layout and capacities $\sigma_{x}, \sigma_{y}$, and $\tau_{x y}$ on two types of top plates

\section{Arranging the bridge girder model for truss optimization}

The implementation of the fixed top plate, the symmetry constraints, and the global section forces into the basic optimization problem (1) is described below. Finally, the complete optimization problem is stated.

\section{Fixed top plate}

The assumed fixed top plate with a total steel thickness $t_{t p}$ is modeled as a plane grid with truss members, cf. Fig. 4 and Fig. 7. These truss members are assigned fixed cross-sectional areas, such that the strength of the truss top plate is equivalent to the assumed top plate. Furthermore, the area of the members in the top plate (top layer of the truss mesh) are discarded as design variables.

A part of the plate with dimensions $a \times b$, as indicated in Fig. 7, is studied in order to identify the truss cross-sectional areas $a_{x}, a_{y}$, and $a_{x y}$ which ensure a strength equivalent to the strength of a solid plate. The plate and truss structures in Fig. 7a and 7b should have the same uni-axial capacities $\sigma_{x}$ and $\sigma_{y}$, and shear capacity $\tau_{x y}$. By demanding force equilibrium between the plate 
and truss structures, the cross-sectional areas are identified as

$$
\begin{aligned}
a_{x} & =t_{t p}(b-\beta a) \\
a_{y} & =t_{t p}(a-\beta b) \\
a_{x y} & =t_{t p} \frac{\beta}{2} \sqrt{a^{2}+b^{2}}
\end{aligned}
$$

where a geometric factor is introduced as $\beta=\frac{1}{2 \sqrt{3}} \frac{(a+b)^{2}}{a^{2}+b^{2}}$ in order to fulfill the von Mises yield criterion. The fixed areas are assigned to the top members in the linear equality constraint

$$
\mathbf{D A}=\mathbf{A}_{0}
$$

where $\mathbf{A}_{0}$ contains the fixed areas $a_{x}, a_{y}$, and $a_{x y}$, and $\mathbf{D}$ is an index matrix linking the design variables to the fixed areas. For truss members positioned along the edge of the domain, only half the area is assigned.

Mapping of symmetry constraints

The symmetry mapping (Fig. 5) is implemented with the following linear equality constraint

$$
\mathbf{S A}=\mathbf{0}
$$

where $\mathbf{S}$ is an index matrix mapping the symmetry between the regions $k, l, m$, and $n$. The member areas in each region, represented by $a_{k}, a_{l}, a_{m}$, and $a_{n}$ in Fig. 5, are mirrored, hence $a_{l}=a_{k}$, 
$a_{m}=a_{k}$, and $a_{n}=a_{k}$, which can be written as

$$
\mathbf{s}_{k} \mathbf{A}=\left[\begin{array}{ccccccccc}
\cdots & -1 & \cdots & 1 & \cdots & 0 & \cdots & 0 & \cdots \\
\cdots & -1 & \cdots & 0 & \cdots & 1 & \cdots & 0 & \cdots \\
\cdots & -1 & \cdots & 0 & \cdots & 0 & \cdots & 1 & \cdots
\end{array}\right]\left[\begin{array}{c}
\vdots \\
a_{k} \\
\vdots \\
a_{l} \\
\vdots \\
a_{m} \\
\vdots \\
a_{n} \\
\vdots
\end{array}\right]=\mathbf{0}
$$

where $\mathbf{s}_{k}$ is the mapping matrix for a single element in region $k$, which is added to $\mathbf{S}$.

Global section forces

Contrary to the distributed load $p$ and the hanger forces $P$, which are applied through the $\mathbf{R}$-vector, the global section forces are not applied to specific nodes on the end surfaces. This is not possible, since the distribution of material from the optimization is unknown. Instead, section forces are defined as a summation of nodal forces on the end surfaces, hence the distribution is unrestricted and given as a result of the optimization. The generic summation of each of the six 


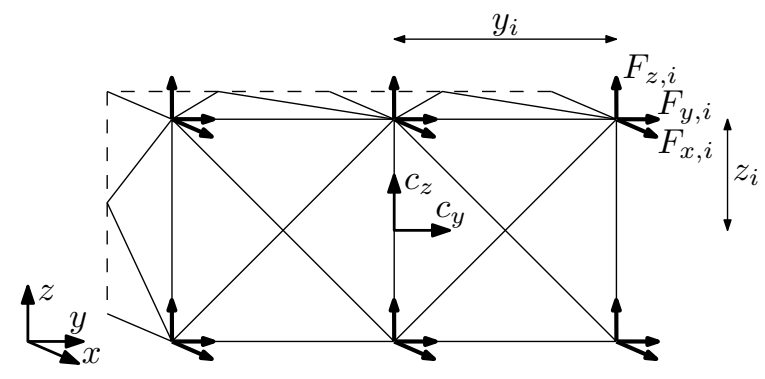

Fig. 8. Contribution of node forces $F$ from node $i$ to the global section forces, with distance $\left(y_{i}, z_{i}\right)$ to the center of the end surface $\left(c_{y}, c_{z}\right)$

section forces for one end surface with $N_{\text {end }}$ nodes is shown below

$$
\begin{aligned}
N_{x} & =\sum_{i=1}^{N_{\text {end }}} F_{x, i} \\
M_{y} & =\sum_{i=1}^{N_{\text {end }}} F_{x, i} \cdot z_{i} \\
M_{z} & =\sum_{i=1}^{N_{\text {end }}}-F_{x, i} \cdot y_{i} \\
V_{y} & =\sum_{i=1}^{N_{\text {end }}} F_{y, i} \\
V_{z} & =\sum_{i=1}^{N_{\text {end }}} F_{z, i} \\
M_{t} & =\sum_{i=1}^{N_{\text {end }}}-F_{y, i} \cdot z_{i}+\sum_{i=1}^{N_{\text {end }}} F_{z, i} \cdot y_{i}
\end{aligned}
$$

where $F_{x, i}, F_{y, i}$, and $F_{z, i}$ are the three nodal forces in node $i$, and $y_{i}$ and $z_{i}$ are the distances to the end surface center $\left(c_{y}, c_{z}\right)$ as indicated in Fig. 8. The nodal forces are found as the sum of components of the bars contributing to node $i$. The sums in (7) are linear functions of the design variables in $\beta$ and the equations can be given as the linear equality constraint

$$
\mathbf{G} \boldsymbol{\beta}=\mathbf{G}_{0}
$$


where $\mathbf{G}$ is a section force equilibrium matrix and $\mathbf{G}_{0}$ is a vector containing the section force values. The vector for the global load case $g$ is given as

$$
\mathbf{G}_{0, g}=\left[N_{x, a, g} M_{y, a, g} M_{z, a, g} V_{y, a, g} V_{z, a, g} M_{t, a, g} N_{x, b, g} M_{y, b, g} M_{z, b, g} V_{y, b, g} V_{z, b, g} M_{t, b, g}\right]^{\top}
$$

The elements in the section force equilibrium matrix $\mathbf{G}$ ensures equilibrium with the section forces in $\mathbf{G}_{0}$ in all degrees of freedom on the two end surfaces. When global section forces are applied through (8) the equilibrium matrix $\mathbf{H}$ and the load vector $\mathbf{R}$ are reduced, hence the degrees of freedom from the end surfaces are removed from $\mathbf{H}$ and $\mathbf{R}$, such that both constraints (1b) and (8) can be fulfilled. The reduced matrix and the reduced vector are renamed $\mathbf{H}_{R}$ and $\mathbf{R}_{R}$, respectively. The complete optimization problem is constructed by adding the three constraints (4), (5), and (8) to the truss optimization problem (1), and by modifying constraint (1b) according to the above

$\begin{array}{ll}\min _{\boldsymbol{\beta}, \mathbf{A}} & \mathbf{A}^{\top} \mathbf{L} \\ \text { s.t. } & \mathbf{H}_{R} \boldsymbol{\beta}=\mathbf{R}_{R} \\ & \mathbf{C} \boldsymbol{\beta}-\mathbf{C}_{m} \mathbf{A} \leq \mathbf{0} \\ & -\mathbf{I} \boldsymbol{\beta}-\mathbf{P A} \leq \mathbf{q} \\ & \mathbf{D A}=\mathbf{A}_{0} \\ & \mathbf{S A}=\mathbf{0} \\ & \mathbf{G} \boldsymbol{\beta}=\mathbf{G}_{0} \\ & \mathbf{K}_{G}\left(\boldsymbol{\beta}_{k}\right)+\mathbf{K}(\mathbf{A}) \geq 0 \quad \forall k=1, \ldots, N_{k}\end{array}$

The above optimization problem, shown in its primal formulation, is solved by its dual formulation, similarly to the technique presented in (Baandrup et al. 2020). The derivation of the dual formulation is shown in Appendix II.

\section{RESULTS}


Initially, methods and girder model are validated, followed by an optimization study of the bridge girder. Since the basic optimization problem (1) was validated and demonstrated in (Poulsen et al. 2020), focus is on the additional constraints (10e), (10f), and (10g). However, since the constraint on the fixed top plate is evident, and the validity of the symmetry constraints is obvious from the result plots, only the implementation of the global section forces needs to be validated. Subsequently, optimization of the bridge girder model with two individual and simple load cases is demonstrated before the optimization results with all 14 load cases are presented. Finally, two parameter studies with varying top plate thickness and domain height, respectively, are carried out.

For all structures, the meshes are described by the number of nodes in the $x$-, $y$ - and $z$-direction by $n_{x}, n_{y}$, and $n_{z}$, respectively, and the connectivity is given by the parameter $r$. If $r=1$ all nodes are connected with elements to their nearest nodes in all directions, if $r=2$ all nodes are connected to the nearest as well as the next-to-nearest nodes in all directions, and so on. In all cases the material parameters are given as $E=210 \mathrm{GPa}$ and $f_{y}=335 \mathrm{MPa}$, equivalent to the Osman Gazi Bridge. Results with and without the stability constraints are shown. When stability constraints are included, also the heuristic methods to reduce truss complexity are included.

The code was implemented in Matlab R2016b (MATLAB 2016) and the convex solver was Mosek version 8.1.0.62 (MOSEK 2018).

\section{Validation of global section force implementation}

The implementation of the global section forces are validated through a study of the six individual section forces applied to a cubical domain. The cube model with dimension $L=5 \mathrm{~m}$, boundary conditions, and loads are seen in Fig. 9. The boundary conditions are applied only to avoid a singular system, since all loads are in equilibrium. The loads are defined as $N_{x}=1 \mathrm{MN}$, $M_{y}=2.5 \mathrm{MNm}, M_{z}=2.5 \mathrm{MNm}, V_{y}=1 \mathrm{MN}, V_{z}=1 \mathrm{MN}$, and $M_{t}=5 \mathrm{MNm}$. To apply shear, counteracting bending moments $-M_{z}$ and $M_{y}$ are applied together with $V_{y}$ and $V_{z}$, respectively. The mesh parameters are given as $n_{x}=n_{y}=n_{z}=3$ and $r=2$ (all nodes inter-connected), generating $N_{e}=335$ elements in the ground-structure, seen in Fig. 10.

Initially, the cube model is optimized without the stability constraints, hence problem (10) 


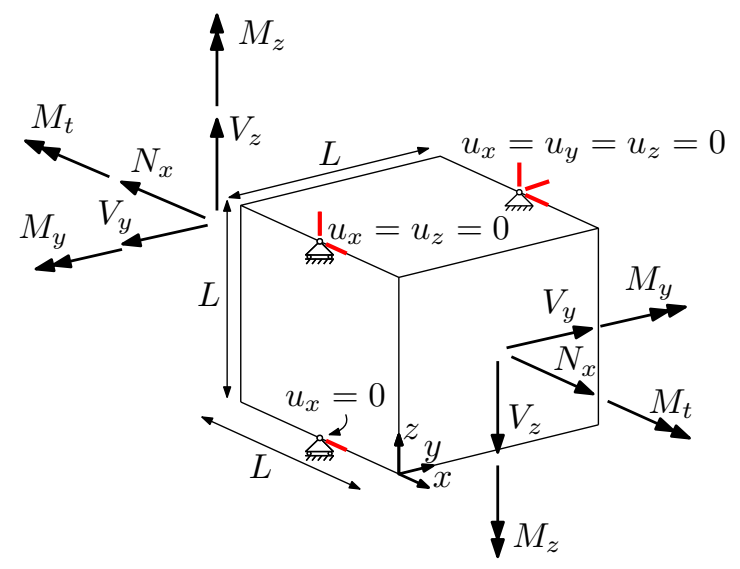

Fig. 9. Domain, boundary conditions, and loads of cube model for validation

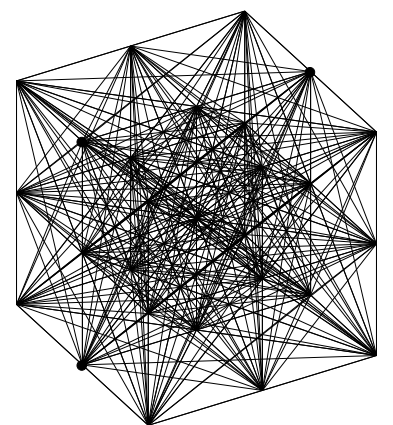

Fig. 10. Initial ground-structure of cube model, $N_{e}=335$

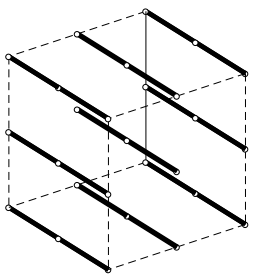

(a) $N_{x}$

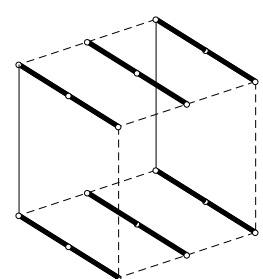

(b) $M_{y}$

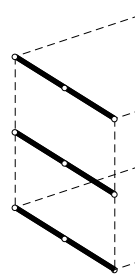

(c) $M_{z}$

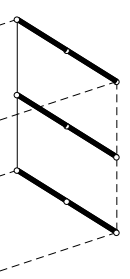

(d) $V_{y}$ and $M_{z}$

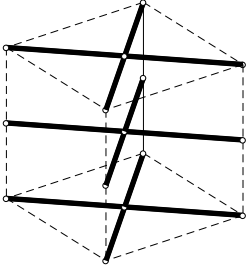

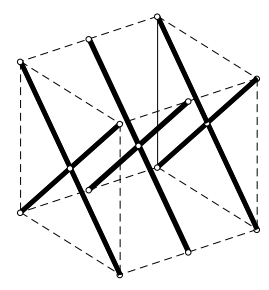

(e) $V_{z}$ and $M_{y}$

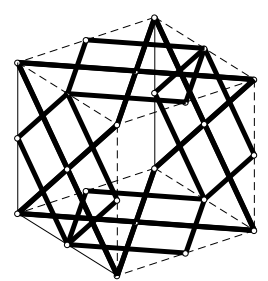

(f) $M_{t}$

Fig. 11. Solutions of cube model for six individual global section forces, with symmetry, without stability constraints. Boundary of domain indicated by dashed lines 


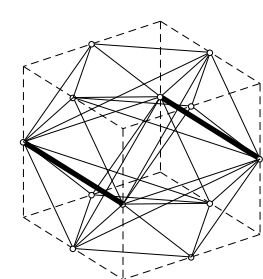

(a) $N_{x}$

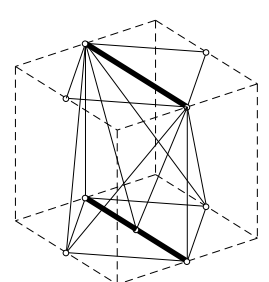

(b) $M_{y}$

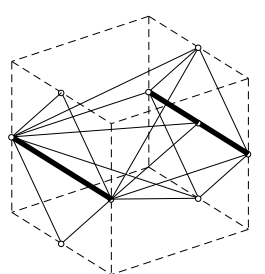

(c) $M_{z}$

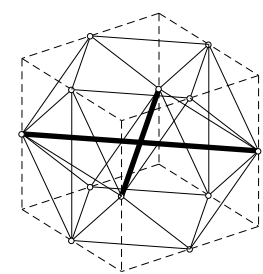

(d) $V_{y}$ and $M_{z}$

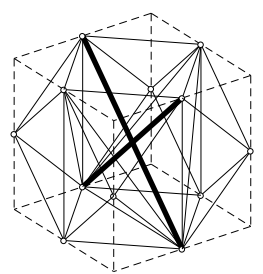

(e) $V_{z}$ and $M_{y}$

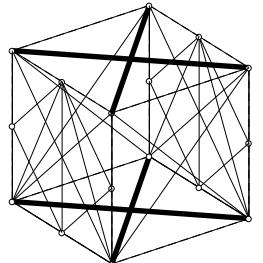

(f) $M_{t}$

Fig. 12. Solutions of cube model for six individual global section forces, with symmetry, and stability constraints. Boundary of domain indicated by dashed lines

et al. 2020), the inclusion of global stability constraints introduces many thin members, in addition to the main members, to ensure overall global stability. Furthermore, the inclusion of local stability constraints leads to fewer but larger main members, as seen in all cases when Fig. 12 is compared to Fig. 11. The reason for this is found in the benefit of collecting material in fewer and larger members, being less prone to local instability, as compared to many slender members. Finally it is emphasized, when including local stability, the optimization problem becomes nonconvex, hence no global optimum is guaranteed, instead many local optima may exist.

\section{Optimization of bridge girder model}

For all cases of the bridge girder optimization, the same initial ground-structure is applied. The mesh is seen in Fig. 13 and defined by an initial grid of $n_{x}=9, n_{y}=11$, and $n_{z}=3$ nodes with a connectivity $r=2$. The node grid and mesh are adapted to the shape of the domain and consist in total of $N=243$ nodes and $N_{e}=6,665$ elements.

When visualizing results a threshold is applied to members with zero or negligible crosssectional areas, for clarity. Two threshold values, relative to the largest cross-sectional area, are applied to identify the main structure $\left(N_{e, \text { Main }} \mid a_{e}>0.1 a_{e, \max }\right)$ and the detailed structure $\left(N_{e, \text { Det. }} \mid a_{e}>0.01 a_{e, \max }\right)$, respectively.

The objective function of volume $V\left[\mathrm{~m}^{3}\right],(10 \mathrm{a})$, is transformed to weight per meter of girder, $W=V \cdot \rho / 25 \mathrm{~m}$, where the density of steel is given as $\rho=7.85 \mathrm{ton} / \mathrm{m}^{3}$. For comparison, the weight (without walkway) of the Osman Gazi Bridge is $11.13 \mathrm{ton} / \mathrm{m}$, where the top part (top plate and troughs) accounts for 5.25 ton $/ \mathrm{m}(47.2 \%)$, and the lower part accounts for 5.88 ton $/ \mathrm{m}$. The assumed 


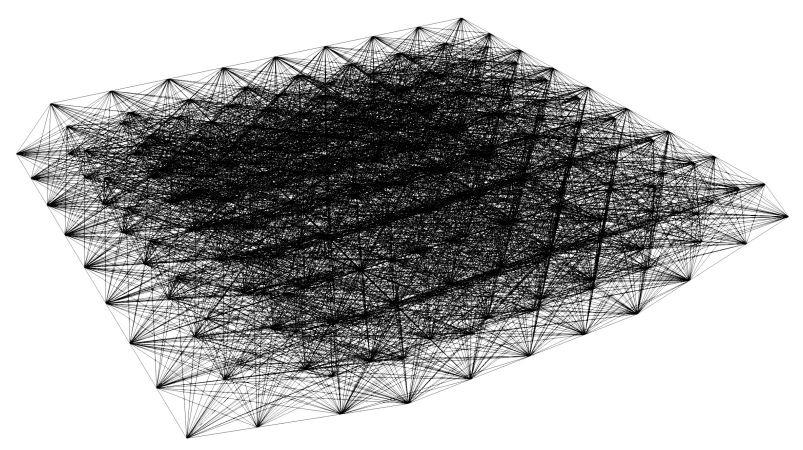

(a) Perspective view

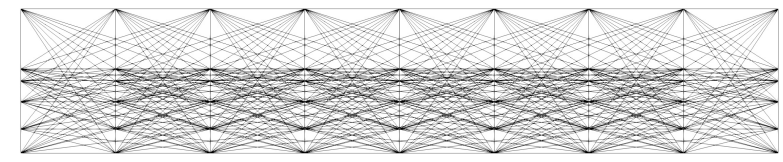

(c) Side view

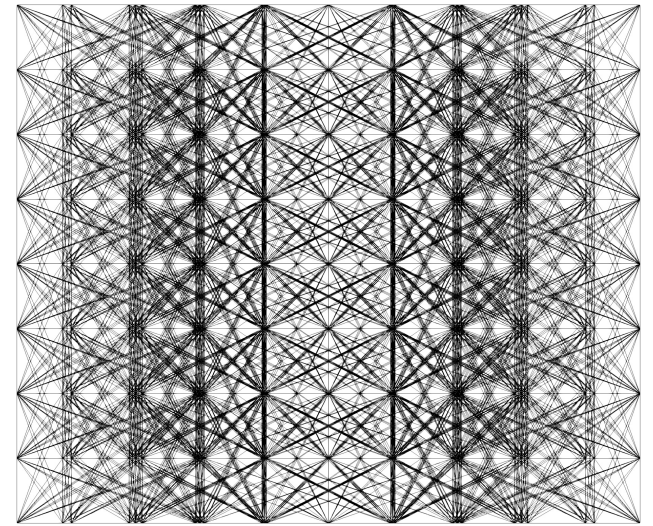

(b) Top view

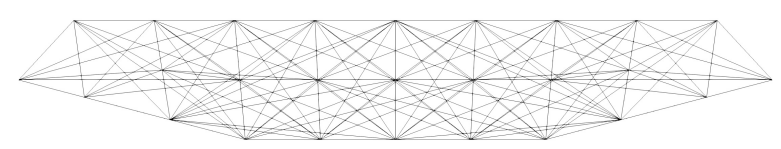

(d) Front view

Fig. 13. Initial ground-structure of bridge girder section, $N_{e}=6,665$

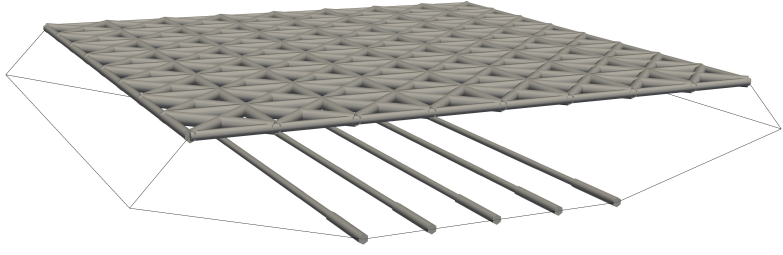

(a) Without stability constraints

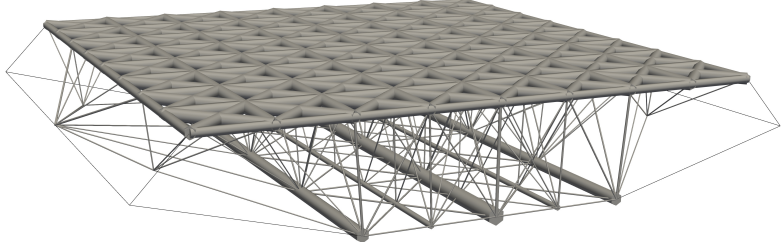

(b) With stability constraints

Fig. 14. Bridge girder model optimized for a single load case of pure bending moment $M_{y}=$ $242 \mathrm{MNm}$ applied at both end surfaces. Perspective view with truss top plate. Boundary of domain indicated by thin black lines

fixed top plate of thickness $t_{t p}=20 \mathrm{~mm}$ accounts for $4.03 \mathrm{ton} / \mathrm{m}$ in the truss girder designs.

\section{Optimization with a single load case}

Firstly, the bridge girder model is subject to a pure bending moment $M_{y}=242 \mathrm{MNm}$ (equivalent to the largest bending moment in the 12 global load cases) at both end surfaces, similarly to the cube model in Fig. $11 \mathrm{~b}$ and $12 \mathrm{~b}$. The optimization problem is solved with and without the stability constraints (10d) and (10h). The results are seen in Fig. 14. It is seen in Fig. 14a how the structure is optimized to carry the bending moment, with material distributed in top and bottom to maximize the second moment of area. In Fig. 14b the effect of the global stability constraint is seen 


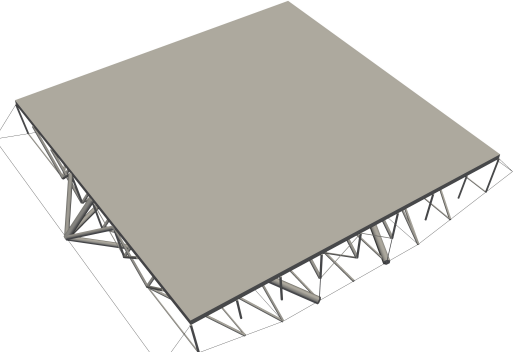

(a) Perspective view, with top plate

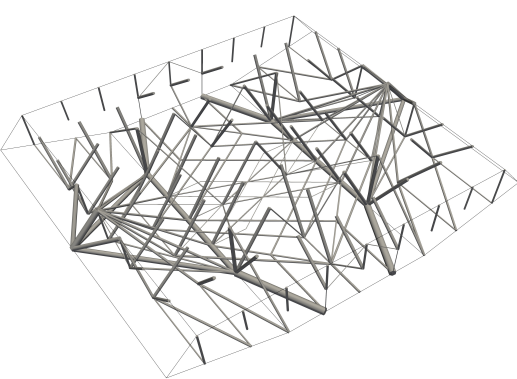

(b) Perspective view, without top plate

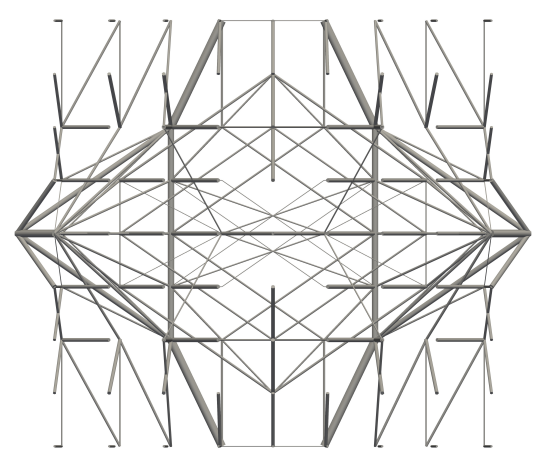

(c) Top view, without top plate

Fig. 15. Bridge girder result optimized for a single load case of distributed load and hanger forces (LC 13), $W=4.27 \mathrm{ton} / \mathrm{m}$. Detailed structure, $N_{e, \text { Det. }}=382$. Boundary of domain indicated by thin black lines on perspective views

in the many additional members. Furthermore, the effect of the local stability constraint is seen in the lower part (in compression), where the material is mainly concentrated in three members, as opposed to the five members in Fig. 14a. Despite the effects of the stability constraints, the structure is clearly still optimized to carry the bending moment.

Secondly, the bridge girder model is optimized for a single local load case with distributed load over the entire top surface and equivalent hanger forces (LC 13 in Table 1 in Appendix I). The complete optimization problem, (10), including stability and symmetry constraints, and the fixed top plate, is solved. The optimized girder, visualized with the detailed structure of $N_{e \text {,Det. }}=382$ elements $\left(N_{e, \text { Main }}=286\right)$, is seen in Fig. 15. From the figure it is seen how the material is distributed more densely close to the hanger anchorage, to which all distributed surface load is transferred, and hence the forces are the largest. On the contrary, the amount of material decreases towards the center of the girder and towards the center line between hangers. Thus, the structure is clearly optimized to carry the distributed load to the hangers. The weight is found to $4.27 \mathrm{ton} / \mathrm{m}$, where the top plate of $4.03 \mathrm{ton} / \mathrm{m}$ accounts for $94.4 \%$ and the lower part thus accounts for 0.24 ton $/ \mathrm{m}$. The large ratio between the weight of the upper and lower parts indicates that the top plate is oversized for this less severe load case. 


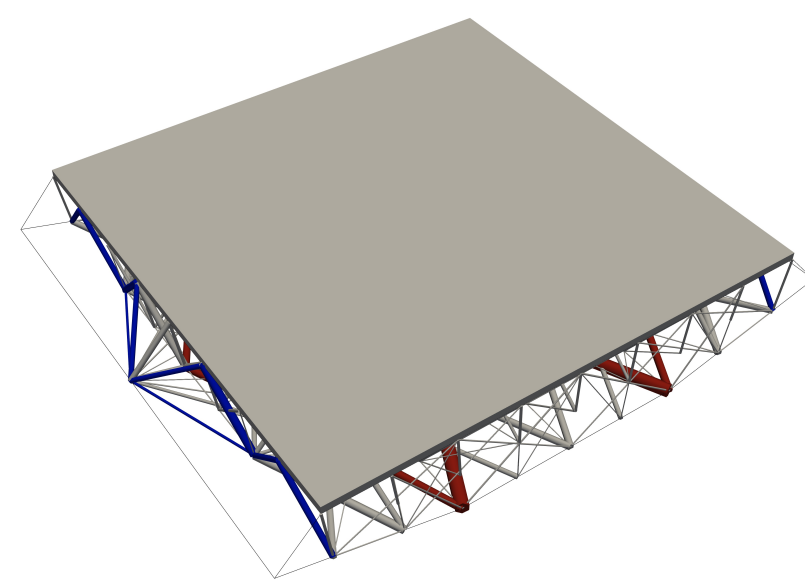

(a) With top plate

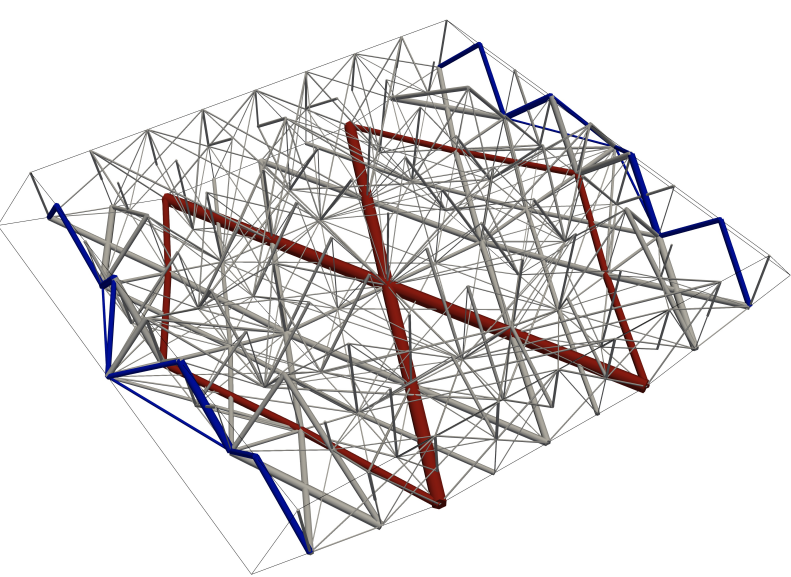

(b) Without top plate

Fig. 16. Bridge girder result optimized for 14 load cases (LC 1-14), $W=6.09$ ton $/ \mathrm{m}$. Perspective view of detailed structure, $N_{e \text {,Det. }}=472$. Boundary of domain indicated by thin black lines

\section{Optimization with 14 load cases}

Next, the bridge girder model is optimized for all 14 load cases (LC 1-14 in Table 1 in Appendix I). A single section of the optimized girder, visualized with the detailed structure of $N_{e, \text { Det. }}=472$ elements, is seen in Fig. 16. Three sections of the continuous girder are shown together in Fig. 17, to emphasize the design. For clarity, only the main structure with $N_{e, \text { Main }}=344$ elements per section is shown. In both Fig. 16 and 17 notable members are highlighted to enhance the design concept.

In Fig. 16 and 17 a significantly different design is seen, compared to the one in Fig. 15. The effects from the global section forces are clearly visible, in particular the large torsion and bending moments are governing the design. Hence, a torsion grid along the circumference of the domain is seen, as well as large longitudinal members in the lower part of the domain. Furthermore, the optimized design is very different from the conventional design, Fig. 2. Not only because truss structures are studied, but also due to the overall structural concept. Loads are carried more directly to the hangers, and transferred to the main bottom grid, to be carried by efficient tension members. Thus, the material is utilized more efficiently, compared to the conventional design where loads are carried to the hangers via perpendicular plate structures. In particular, two important design principles are identified. The first principle which is highlighted in red (dark grey in greyscale), 


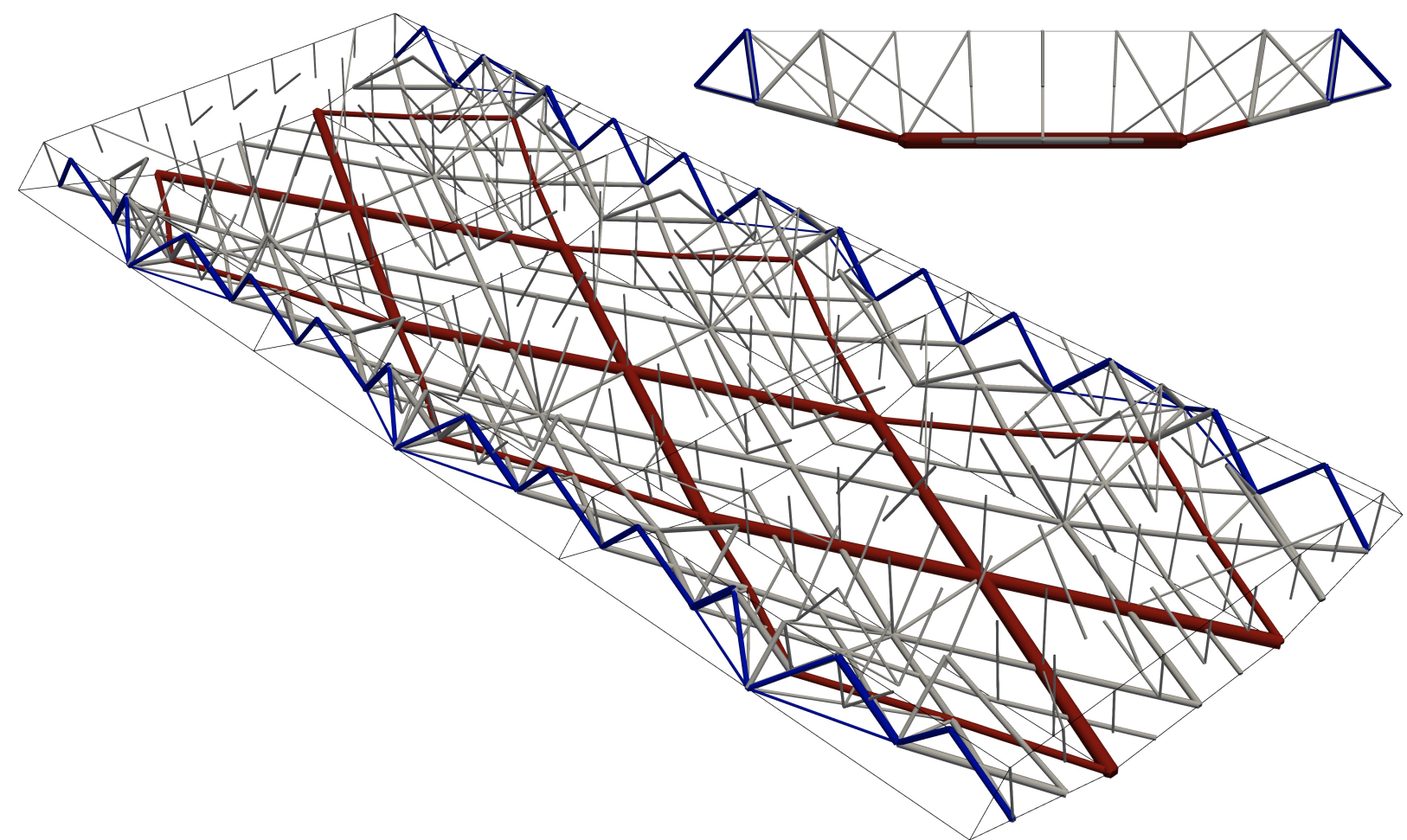

(a) Perspective and section view. Boundary of domain indicated by thin black lines

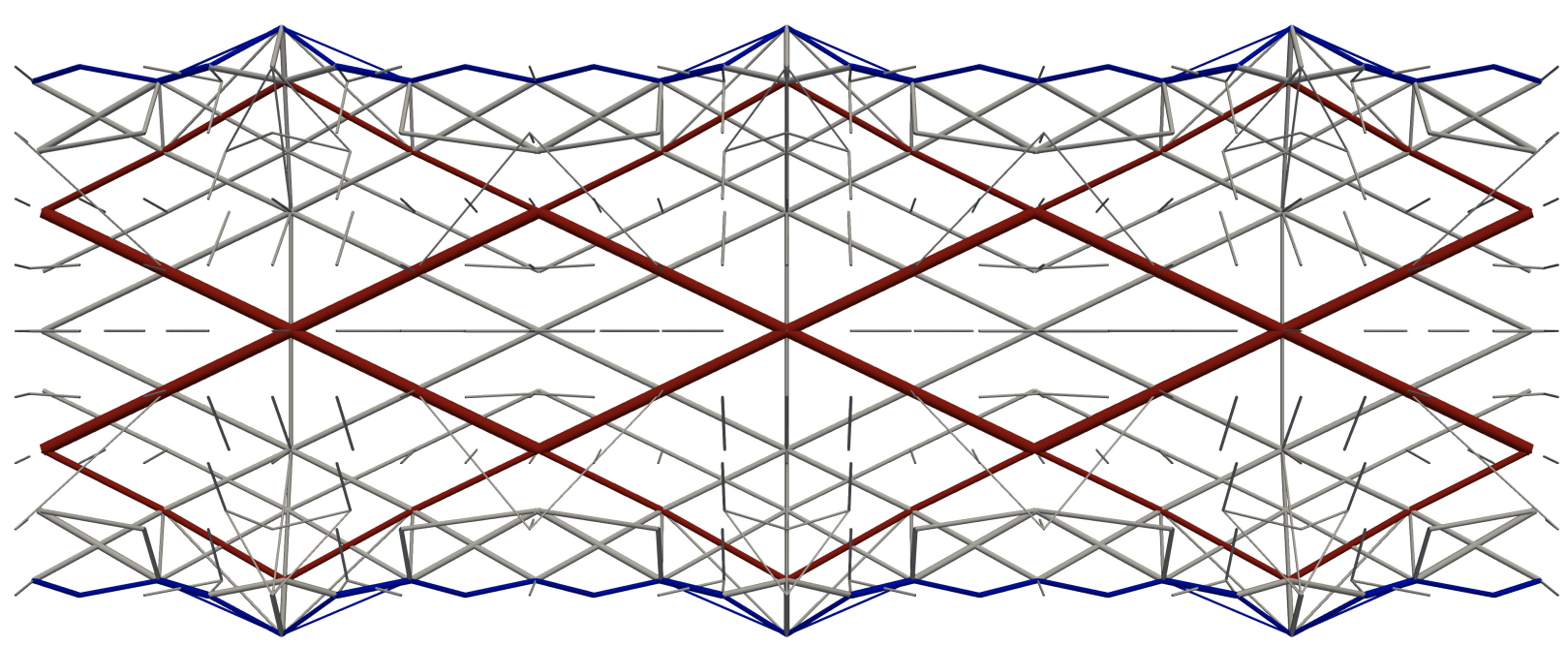

(b) Top view

Fig. 17. Bridge girder result optimized for 14 load cases (LC 1-14), three spans, $W=6.09$ ton/m. Main structure without top plate, $N_{e, \text { Main }}=344$ per section 
includes the largest bottom members spanning across two sections, from the hanger in one side, through the neighboring section, to the hanger in the opposite side. Thus, the interaction between the sections reaches further than to the nearest neighboring sections in order to support bending and torsional moments efficiently. This principle emerges from the optimization, although the mesh (Fig. 13) allows for a span between hangers crossing a single section only. The second principle which is highlighted in blue (black in greyscale), is characterized by the curved narrowing of the girder between hangers, without exploiting the entire domain width.

The weight of the girder is found to $6.09 \mathrm{ton} / \mathrm{m}$, where the weight of the top plate, $4.03 \mathrm{ton} / \mathrm{m}$, accounts for $66.2 \%$ and the weight of the lower part is $2.06 \mathrm{ton} / \mathrm{m}$. The total weight is equivalent to $54.7 \%$ of the Osman Gazi Bridge. This significant weight reduction indicates the large potential in alternative truss based design concepts. In all weight measures, the contribution from connections (weldings and bolts) has been neglected. Furthermore, construction costs have not been considered. However, concerns about construction cost are subordinate to self-weight issues, which are crucial to the possible achievement of very-long suspension bridges (main span beyond $2 \mathrm{~km}$ ).

The ratio between the weight of the top plate and the total weight (66.2\%) is higher compared to the Osman Gazi Bridge (47.2\%), indicating a conservative choice of the equivalent top plate thickness of $20 \mathrm{~mm}$. Therefore, the effect of reducing the top plate thickness is studied in the following.

\section{Top plate thickness}

Since the top plate thickness is fixed during optimization, a parameter study of varying thickness, $t_{t p}$, is carried out. The complete girder model with all 14 load cases is studied with fixed thicknesses varying from $10 \mathrm{~mm}$ to $25 \mathrm{~mm}$, with $5 \mathrm{~mm}$ intervals. The results of the study are summarized in Table 2, where the Osman Gazi Bridge has been included for reference.

In Case 3, the ratio between the weight of the top plate and the total weight is higher compared to the ratio of the conventionally designed Osman Gazi Bridge, indicating a further potential saving by reducing the top plate thickness. In Case 1 , with $t_{t p}=10 \mathrm{~mm}$, the ratio is reduced to $49.4 \%$ which is close to the conventional design. With $t_{t p}=10 \mathrm{~mm}$ the total weight of $4.09 \mathrm{ton} / \mathrm{m}$ is equivalent 
TABLE 2. Study of varying top plate thickness $t_{t p}$ for the Osman Gazi bridge and four truss girder cases. Weight savings are given relative to the total weight of the Osman Gazi Bridge. *Equivalent plate thickness of the orthotropic top deck (top plate and troughs)

\begin{tabular}{lllllll}
\hline \hline Case & $t_{t p}$ & $\begin{array}{l}\text { Total } \\
\text { weight } \\
{[\mathrm{ton} / \mathrm{m}]}\end{array}$ & $\begin{array}{l}\text { Weight } \\
\text { saving } \\
{[-]}\end{array}$ & $\begin{array}{l}\text { Weight of } \\
\text { top plate } \\
{[\text { ton } / \mathrm{m}]}\end{array}$ & $\begin{array}{l}\text { Weight of } \\
\text { lower part } \\
\text { [ton/m] }\end{array}$ & $\begin{array}{l}\text { Ratio between top } \\
\text { plate and total weight } \\
{[-]}\end{array}$ \\
\hline Osman Gazi & $26^{*}$ & 11.13 & - & 5.25 & 5.88 & $47.2 \%$ \\
\hline 1 & 10 & 4.09 & $63.2 \%$ & 2.02 & 2.07 & $49.4 \%$ \\
2 & 15 & 5.11 & $54.1 \%$ & 3.03 & 2.08 & $59.3 \%$ \\
3 & 20 & 6.09 & $45.3 \%$ & 4.03 & 2.06 & $66.2 \%$ \\
4 & 25 & 7.09 & $35.3 \%$ & 5.04 & 2.05 & $71.1 \%$ \\
\hline \hline
\end{tabular}

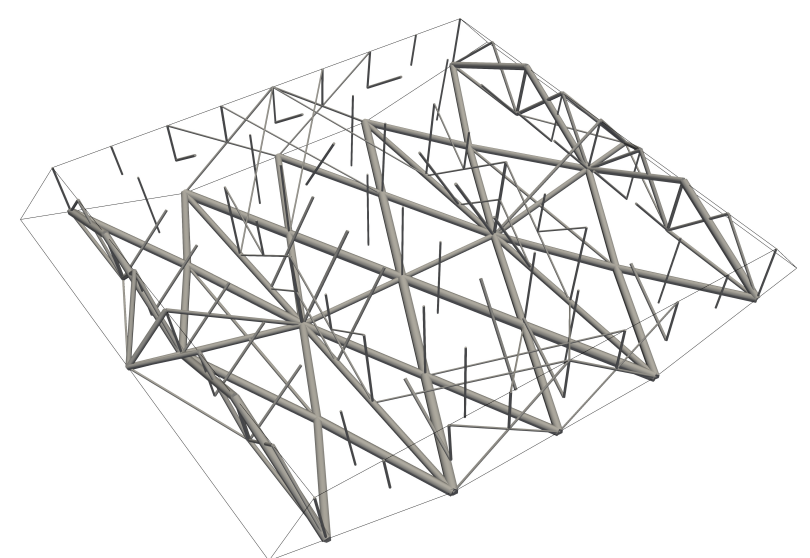

(a) Top plate thickness $t_{t p}=10 \mathrm{~mm}, W=4.09 \mathrm{ton} / \mathrm{m}$, $N_{e, \text { Main }}=342$

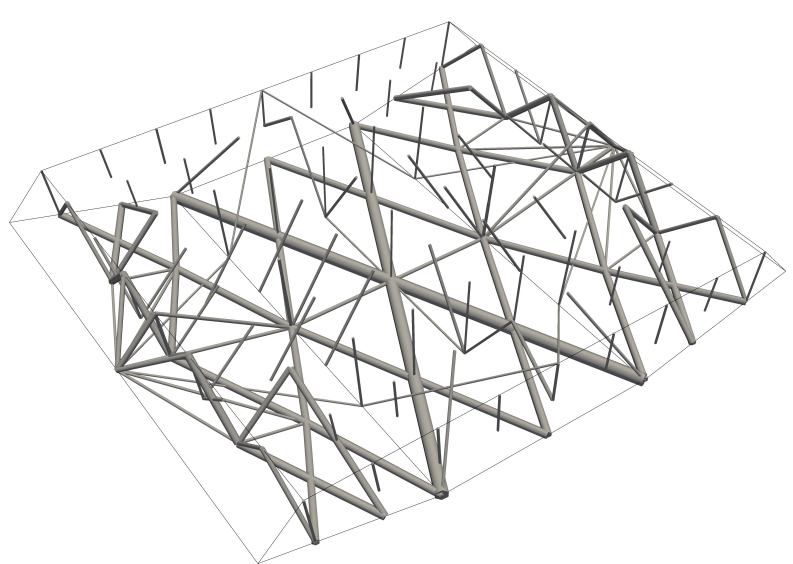

(b) Top plate thickness $t_{t p}=15 \mathrm{~mm}, W=5.11 \mathrm{ton} / \mathrm{m}$, $N_{e, \text { Main }}=332$

Fig. 18. Bridge girder results (14 load cases) for Case 1 and 2 in Table 2, perspective view of main structure without top plate. Boundary of domain indicated by thin black lines

to $36.7 \%$ of the Osman Gazi Bridge. However, an equivalent top plate of $10 \mathrm{~mm}$ thickness is most likely not capable of spanning $3 \mathrm{~m}$ while carrying the traffic. With a thicker equivalent top plate of $t_{t p}=15 \mathrm{~mm}$, the total weight of $5.11 \mathrm{ton} / \mathrm{m}$ is equivalent to $45.9 \%$ of the Osman Gazis Bridge.

The truss girder designs for Case 1 and 2 are seen in Fig. 18, visualizing the main structure of a single section. The equivalent visualization of Case 3 is seen in Fig. 17a, while the visualization of Case 4 has been left out. In the designs of both Case 1 and 2, the bottom grid is more uniform, compared to Fig. 17a where the grid consists of distinct primary and secondary members. This effect can be seen as a result of the reduced top plate thickness, hence more material is concentrated 
TABLE 3. Study of varying domain height $H$ for four cases

\begin{tabular}{lcccc}
\hline \hline Case: & 1 & 2 & 3 & 4 \\
\hline Height $H[\mathrm{~m}]$ & 4.75 & 6.0 & 8.0 & 10.0 \\
Weight $W[$ ton $/ \mathrm{m}]$ & 6.09 & 5.77 & 5.50 & 5.42 \\
\hline \hline
\end{tabular}

in the bottom of the domain. Similarly, in Case 1 pronounced longitudinal members are formed in the bottom to counteract the decreased longitudinal strength in the top part, due to the thinner top plate. Despite the changes to the design, the main principles are similar to Case 3.

\section{Domain height}

Finally, a study of the effect on the girder weight from varying the domain height $H$ is carried out. The study is carried out by increasing the height $H$ (Fig. 3) while the mesh given in Fig. 13 scales. A summary of the study of domain heights from $4.75 \mathrm{~m}$ to $10 \mathrm{~m}$ is seen in Table 3 . From the table it is seen that by increasing the domain height, the weight decreases. This effect is expected, due to the benefits from increased height on the torsion and bending moment capacities. However, in general the weight reduction is modest. Further, the effect decreases with increasing height, thus the change from Case 3 to 4 is significantly smaller than from Case 1 to 2 .

\section{CONCLUSIONS}

Truss topology optimization, including stress constraints, as well as global and local stability constraints, was applied in the study of new conceptual designs for girders in cable-supported bridges. In addition to the basic optimization problem, novel constraints were added to account for an assumed top plate, symmetry and the application of global section forces, in order to establish the necessary conditions to model a bridge girder section. The girder model was subject to local and global loads, and optimized with the goal of minimizing the total weight. The implementation of the imposed global section forces was validated by simple examples, both without and with stability constraints. Subsequently, the bridge girder model was studied under individual and simple load cases. Finally, optimization including all considered load cases was carried out in order to identify potential new design concepts and weight savings. Due to the truss structure approach, designs 
showing new and efficient load carrying principles, which are significantly different from the conventional design, emerged from the optimization. Here, the main structure consisted of a torsion grid along the circumference of the domain, as well as large members in the bottom to carry bending moments. Furthermore, load paths were oriented more directly towards the hanger attachments, and running through the bottom part to benefit from tension members. The total girder weight of $6.09 \mathrm{ton} / \mathrm{m}$ was equivalent to only $54.7 \%$ of the conventionally designed girder of the Osman Gazi Bridge. Hence, the significant weight reduction and new design principles indicate the potential of these alternative design concepts. Moreover, the two parameter studies on the top plate thickness and the domain height indicate possible further weight reduction. The most significant effect was found in reducing the top plate thickness, whereby the ratio between the weight of the top plate and the total weight of the girder approaches the ratio of the conventional design.

In general, the new design principles and possible weight reductions indicate the potential of alternative truss based design concepts. Although the construction cost has been neglected, the potentials are highly relevant to very-long suspension bridges with spans beyond $2 \mathrm{~km}$, for which low self-weight is crucial. 


\section{APPENDIX I. TABLE OF LOAD CASES}

The 12 global load cases (LC 1-12) and two local load cases (LC 13-14) are seen in Table 1. Load cases 1-12 are identified from a global beam model of the Osman Gazi Bridge. Each of these is identified based on the maximum and minimum section forces in the girder on end surface $a$, hence $\mathrm{LC} 1$ is derived from the maximum $N_{x}, \mathrm{LC} 2$ from minimum $N_{x}, \mathrm{LC} 3$ from maximum $M_{y}$ and so on. As seen from the table load case 6 and 8 are identical, hence the minimum bending moment $M_{z}$ and minimum shear force $V_{y}$ occur in the same load case and at the same girder location in the global beam model. Consequently, one of these load cases can be neglected in the optimization to reduce the problem size. 


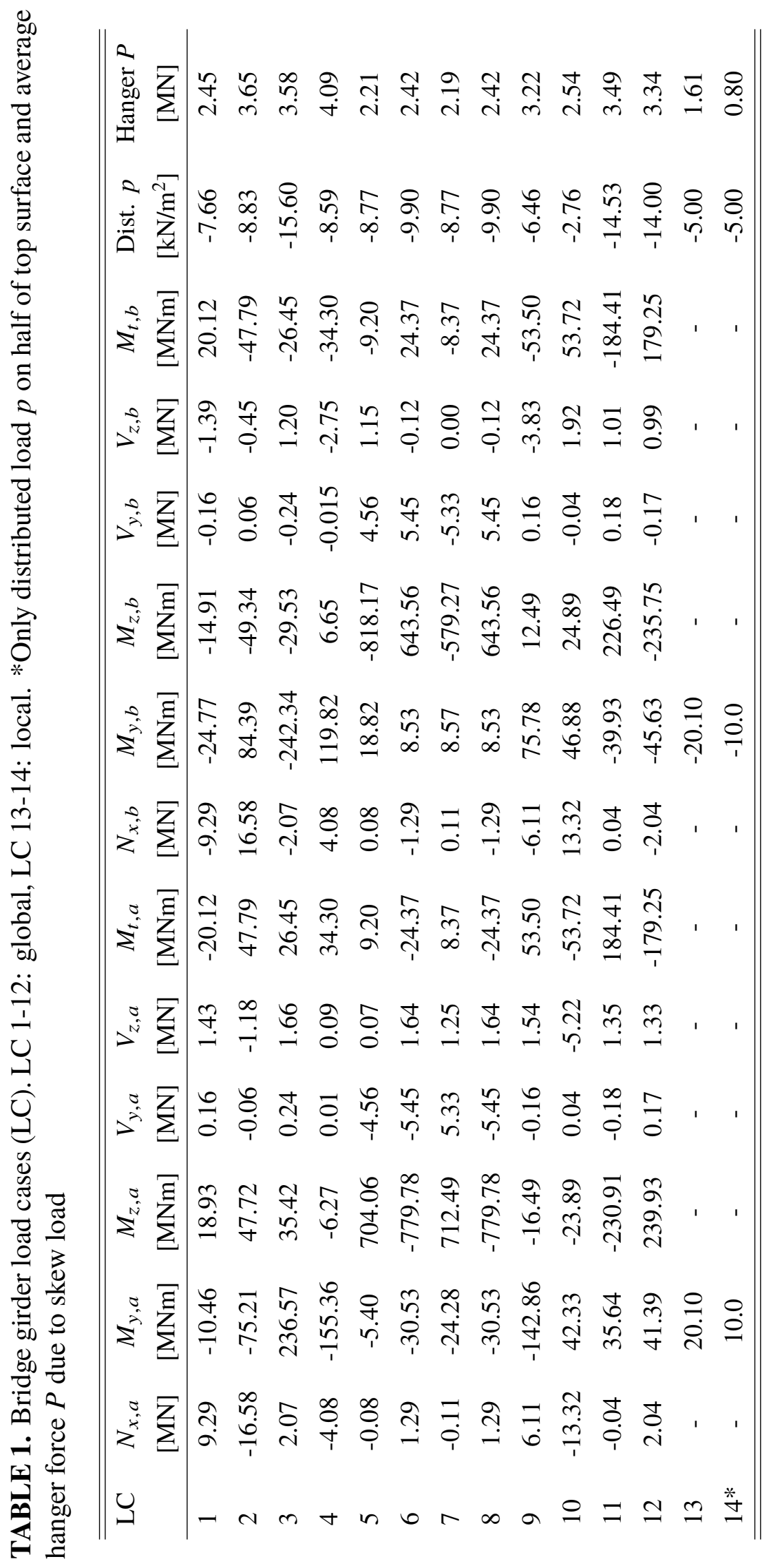




\section{APPENDIX II. DUAL FORMULATION OF COMPLETE OPTIMIZATION PROBLEM}

Similar to the technique in (Baandrup et al. 2020) the dual formulation of problem (10) is derived in the following. To handle the semidefinite constraint (10h) in the formulation of the Lagrangian of the problem, a semidefinite dual variable $\mathbf{Y}_{k} \forall k=1, \ldots, N_{k}$ is introduced. To derive the Lagrangian function a self-adjoint operator on $\mathbf{Y}_{k}$ is defined as $\sum_{k=1}^{N_{k}}\left\langle\mathbf{K}_{S, k}\left(\boldsymbol{\beta}_{k}, \mathbf{A}\right), \mathbf{Y}_{k}\right\rangle=$ $\left[\begin{array}{ll}\boldsymbol{\beta}^{\top} & \mathbf{A}^{\top}\end{array}\right] \sum_{k=1}^{N_{k}} \mathbf{K}_{S, k}^{*}\left(\mathbf{Y}_{k}\right)$. The reader is referred to (Baandrup et al. 2020) for details on the adjoint operator. The Lagrangian of problem (10) is given as

$$
\begin{aligned}
& \mathcal{L}\left(\boldsymbol{\beta}, \mathbf{A}, \mathbf{y}, \mathbf{z}, \mathbf{t}, \mathbf{u}, \mathbf{v}, \mathbf{w}, \mathbf{Y}_{k}\right)=\left[\begin{array}{ll}
\mathbf{0} & \mathbf{L}^{\top}
\end{array}\right]\left[\begin{array}{l}
\boldsymbol{\beta} \\
\mathbf{A}
\end{array}\right]-\mathbf{y}^{\top}\left(\left[\begin{array}{ll}
\mathbf{H}_{R} & \mathbf{0}
\end{array}\right]\left[\begin{array}{l}
\boldsymbol{\beta} \\
\mathbf{A}
\end{array}\right]-\mathbf{R}_{R}\right) \\
& +\mathbf{z}^{\top}\left(\left[\begin{array}{ll}
\mathbf{C} & -\mathbf{C}_{m}
\end{array}\right]\left[\begin{array}{l}
\boldsymbol{\beta} \\
\mathbf{A}
\end{array}\right]\right)+\mathbf{t}^{\top}\left(\left[\begin{array}{ll}
-\mathbf{I} & -\mathbf{P}
\end{array}\right]\left[\begin{array}{l}
\boldsymbol{\beta} \\
\mathbf{A}
\end{array}\right]-\mathbf{q}\right)-\mathbf{u}^{\top}\left(\left[\begin{array}{ll}
\mathbf{0} & \mathbf{D}
\end{array}\right]\left[\begin{array}{l}
\boldsymbol{\beta} \\
\mathbf{A}
\end{array}\right]-\mathbf{A}_{0}\right) \\
& -\mathbf{v}^{\top}\left(\left[\begin{array}{ll}
\mathbf{0} & \mathbf{S}
\end{array}\right]\left[\begin{array}{l}
\boldsymbol{\beta} \\
\mathbf{A}
\end{array}\right]\right)-\mathbf{w}^{\top}\left(\left[\begin{array}{ll}
\mathbf{G} & \mathbf{0}
\end{array}\right]\left[\begin{array}{l}
\boldsymbol{\beta} \\
\mathbf{A}
\end{array}\right]-\mathbf{G}_{0}\right)-\sum_{k=1}^{N_{k}}\left\langle\mathbf{K}_{S, k}\left(\boldsymbol{\beta}_{k}, \mathbf{A}\right), \mathbf{Y}_{k}\right\rangle \\
& =\left[\begin{array}{ll}
\boldsymbol{\beta}^{\top} & \mathbf{L}^{\top}
\end{array}\right]\left(\left[\begin{array}{l}
\mathbf{0} \\
\mathbf{L}
\end{array}\right]-\left[\begin{array}{c}
\mathbf{H}_{R}^{\top} \\
\mathbf{0}
\end{array}\right] \mathbf{y}+\left[\begin{array}{c}
\mathbf{C}^{\top} \\
-\mathbf{C}_{m}^{\top}
\end{array}\right] \mathbf{z}+\left[\begin{array}{c}
-\mathbf{I} \\
-\mathbf{P}^{\top}
\end{array}\right] \mathbf{t}-\left[\begin{array}{c}
\mathbf{0} \\
\mathbf{D}^{\top}
\end{array}\right] \mathbf{u}-\left[\begin{array}{c}
\mathbf{0} \\
\mathbf{S}^{\top}
\end{array}\right] \mathbf{v}\right. \\
& \left.-\left[\begin{array}{c}
\mathbf{G}^{\top} \\
\mathbf{0}
\end{array}\right] \mathbf{w}-\sum_{k=1}^{N_{k}} \mathbf{K}_{S, k}^{*}\left(\mathbf{Y}_{k}\right)\right)+\mathbf{R}_{R}^{\top} \mathbf{y}-\mathbf{q}^{\top} \mathbf{t}+\mathbf{A}_{0}^{\top} \mathbf{u}+\mathbf{G}_{0}^{\top} \mathbf{w}
\end{aligned}
$$


By differentiating (11b) w.r.t. the primal variables $(\boldsymbol{\beta}, \mathbf{A})$ the dual of (10) can be formed as

$$
\begin{aligned}
& \min _{\mathbf{y}, \mathbf{z}, \mathbf{t}, \mathbf{u}, \mathbf{v}, \mathbf{w}, \mathbf{Y}_{k}}-\mathbf{R}_{R}^{\top} \mathbf{y}+\mathbf{q}^{\top} \mathbf{t}-\mathbf{A}_{0}^{\top} \mathbf{u}-\mathbf{G}_{0}^{\top} \mathbf{w} \\
& \text { s.t. } \quad\left[\begin{array}{c}
\mathbf{H}_{R}^{\top} \\
\mathbf{0}
\end{array}\right] \mathbf{y}-\left[\begin{array}{c}
\mathbf{C}^{\top} \\
-\mathbf{C}_{m}^{\top}
\end{array}\right] \mathbf{z}+\left[\begin{array}{c}
\mathbf{I} \\
\mathbf{P}^{\top}
\end{array}\right] \mathbf{t}+\left[\begin{array}{c}
\mathbf{0} \\
\mathbf{D}^{\top}
\end{array}\right] \mathbf{u}+\left[\begin{array}{c}
\mathbf{0} \\
\mathbf{S}^{\top}
\end{array}\right] \mathbf{v} \\
& +\left[\begin{array}{c}
\mathbf{G}^{\top} \\
\mathbf{0}
\end{array}\right] \mathbf{w}+\sum_{k=1}^{N_{k}} \mathbf{K}_{S, k}^{*}\left(\mathbf{Y}_{k}\right)=\left[\begin{array}{l}
\mathbf{0} \\
\mathbf{L}
\end{array}\right] \\
& \mathbf{z} \geq \mathbf{0} \\
& \mathbf{t} \geq \mathbf{0} \\
& \mathbf{Y}_{k} \geq 0 \quad \forall k=1, \ldots, N_{k}
\end{aligned}
$$

with the dual variables $\mathbf{y}, \mathbf{z}, \mathbf{t}, \mathbf{u}, \mathbf{v}, \mathbf{w}$, and $\mathbf{Y}_{k}$. 
Some or all data, models, or code generated or used during the study are available from the corresponding author by request. This includes the Matlab input files to the demonstrated problems. 


\section{ACKNOWLEDGEMENTS}

The presented work is part of an industrial ph.d. project with the title "Innovative design of steel bridge girders in cable-supported bridges" and is carried out in cooperation with COWI A/S, DTU Civil Engineering and DTU Mechanical Engineering. The project is supported financially by the COWI Foundation grant C-131.02 and Innovation Fund Denmark grant 5189-00112B. 


\section{REFERENCES}

Aygül, M., Al-Emrani, M., and Urushadze, S. (2012). "Modelling and fatigue life assessment of orthotropic bridge deck details using FEM.” International Journal of Fatigue, 40, 129-142.

Baandrup, M., Olesen, J. F., and Poulsen, P. N. (2020). "Large-scale truss optimization including global and local stability." Structural and Multidisciplinary Optimization (in review).

Baandrup, M., Poulsen, P. N., Olesen, J. F., and Polk, H. (2019). "Parametric Optimization of Orthotropic Girders in a Cable-Supported Bridge.” Journal of Bridge Engineering, 24(12).

Backer, H. D., Outtier, A., and Van Bogaert, P. (2006). “Analytical model for the stiffener-to-deck plate detail in orthotropic bridges." Proc. of the 10th East Asia-Pacific Conference on Structural Engineering and Construction, Volume 2, pp. 47-52.

Battista, R. C., Santos, E. F., Vasconcelos, R., and Pfeil, M. S. (2010). “A visco-elastic sandwich solution for orthotropic decks of steel bridges." SDSS'Rio 2010 Stability and ductility of steel structures.

CEN (2002). "Eurocode 1: Actions on structures - Part 1." Report No. EN 1991-1-X:2002, European Committee for Standardization, Brussles, Belgium.

CEN (2003). "Eurocode 1: Actions on structures - Part 2: Traffic on bridges.” Report No. EN19912:2003, European Committee for Standardization, Brussles, Belgium.

Chu, S., Gao, L., Xiao, M., and Li, H. (2018). "Design of sandwich panels with truss cores using explicit topology optimization.” Composite Structures, 210(December), 892-905.

Connor, R. (2004). "Influence of cutout geometry on stresses at welded rib-to-diaphragm connections in steel orthotropic bridge decks." Transportation Research Record: Journal of the Transportation Research Board, 1892, 78-87.

Corte, W.D. (2011). “A review of alternatives for orthotropic bridge deck panels.” Bridge Structures, 7, 95-102.

De Corte, W. (2009). "Parametric study of floorbeam cutouts for orthotropic bridge decks to determine shape factors." Bridge Structures, 5(2-3), 75-85.

Diana, G., Yamasaki, Y., Larsen, A., Rocchi, D., Giappino, S., Argentini, T., Pagani, A., Villani, 
M., Somaschini, C., and Portentoso, M. (2013). "Construction stages of the long span suspension Izmit Bay Bridge: Wind tunnel test assessment." Journal of Wind Engineering and Industrial Aerodynamics, 123, 300-310.

Fettahoglu, A. (2016). "Optimizing rib width to height and rib spacing to deck plate thickness ratios in orthotropic decks." Cogent Engineering, 3(1).

Fisher, J. W. and Dexter, R. J. (1997). "Fatigue cracking of orthotropic steel decks." IABSE reports, 76.

Gimsing, N. J. and Georgakis, C. T. (2012). Cable supported bridges: concept and design. John Wiley \& Sons.

Kozy, B. M. and Connor, R. (2010). "Fatigue Design of Orthotropic Steel Bridges." Structures Congress 2010, Reston, VA, American Society of Civil Engineers, 541-553 (may).

MATLAB (2016). "R2016b documentation." MathWorks.

MOSEK (2018). “The MOSEK optimization toolbox for MATLAB manual. Version 8.1.

Oh, C. K. and Bae, D. (2013). "Fatigue test of an advanced orthotropic steel deck system using high performance steel for bridges.” International Journal of Steel Structures, 13(1), 93-101.

Oh, C. K., Hong, K. J., Bae, D., Do, H., and Han, T. (2011). “Analytical and experimental studies on optimal details of orthotropic steel decks for long span bridges." International Journal of Steel Structures, 11(2), 227-234.

Poulsen, P. N., Olesen, J. F., and Baandrup, M. (2020). "Truss optimization applying finite element limit analysis including global and local stability." Structural and Multidisciplinary Optimization, $62,41-54$.

Song, Y. S. and Ding, Y. L. (2014). "Influence of local geometric parameters on fatigue performance of orthotropic steel deck." Journal of Central South University, 21(5), 2091-2099.

Wolchuk, R. (1999). "Steel orthotropic decks: developments in the 1990s.” Transportation Research Record, 1688(99-0430), 30-37.

Wolchuk, R. and Harris, F. R. (1959). “Orthotropic plate design of steel bridges.” Civil Eng., 38-43. Zhang, Q.-H. (2017). "Review on Fatigue Problems of Orthotropic Steel Bridge Deck.” China 
journal of highway and transport, 30(3). 